\title{
A Peer-Based Approach to Reducing Stigma and Improving Mental Health Support for Medical Students
}

\author{
Shale B Farber, BSc ${ }^{1}$, Simon DG Parlow, BSc ${ }^{1}$, Nicholas P Timmerman, BHSc${ }^{1}$ \\ ${ }^{1}$ Faculty of Medicine, Univeristy of Ottawa
}

A BSTRACT

\begin{abstract}
Medical students experience a tremendous amount of stress during their training, which can have a profound effect on mental wellness. Several medical students at the University of Ottawa have created a peer-based program called Mind the Gap (MtG), which aims to improve mental health support and combat mental health-related stigma within the medical student community. The program consists of monthly meetings that invite students to discuss personal experiences and issues surrounding mental illness. The following article is a commentary outlining the MtG program, including its rationale and goals, and the challenges in implementing this type of program.
\end{abstract}

\section{RÉ S U MÉ}

Les étudiants en médecine vivent un stress énorme au cours de leur formation, ce qui peut avoir un impact profond sur leur bien-être mental. Plusieurs étudiants en médecine à l'Université d'Ottawa ont mis sur pied un programme appelé « Mind the Gap » (MtG), qui vise à améliorer le soutien en santé mentale et à combattre la stigmatisation liée à la santé mentale dans la communauté médicale étudiante. Le programme est composé de rencontres mensuelles qui permettent aux étudiants de discuter de leurs expériences personnelles et des problèmes liés à la maladie mentale. L'article suivant est un commentaire donnant un aperçu du programme MtG, incluant sa raison d'être et ses buts, et les défis qui surviennent lors de la mise en place d'un tel programme.

It is well known that medical students experience a tremendous amount of stress during their training, which may be attributed to a heavy course load, long work hours, stressful transitions to clinical environments, and evaluations by senior trainees and physicians [1]. These elements can have a profound effect on mental wellness. A literature review conducted by Dyrbye et al on medical student distress showed that Canadian and American medical students experience higher rates of depression and psychological distress than the general population; this was found to result in poor academic and clinical performance, substance abuse, and suicidality [1]. A more recent study of seven U.S. medical schools found that $49.6 \%$ of students reported burnout and $11.2 \%$ experienced thoughts of suicide over the past year [2]. Perhaps more troubling is the fact that medical students often fail to access necessary mental health services. A recent study at the University of Michigan Medical School showed that students suffering from depression endorsed perceptions of stigma related to mental illness and were less likely to seek help than their non-depressed colleagues [3]. Common biases emerged in this study, including the perception that mental illness is a form of weakness and that disclosing one's mental illness is risky to one's professional career [3].

There are many available opportunities within the medical school curriculum that may help reduce mental health stigma and improve support for medical students. This has been an im- portant focus of the Canadian Medical Association (CMA), which recently published a report outlining a mental health strategy for physicians and trainees in Canada [4]. As part of this strategy, the report discusses the importance of fostering support among medical students and addressing mental health stigma in the medical school environment [4]. The report also discusses the value of utilizing a continuum of programs and services that address mental health issues, such as workshops focused on building positive coping strategies and resilience [4]. Despite these recommendations, gaps still remain in resources and supports available to Canadian medical students.

In light of these recommendations, several medical students at the University of Ottawa have created a program to improve support and to combat stigma within the medical student community. The program, known as Mind the Gap (MtG), consists of monthly one-hour meetings that are exclusively open to students in undergraduate medical training. At each meeting, students are invited to share personal experiences related to mental illness, to discuss the barriers that prevent students from accessing support, and also to share positive coping behaviours and strategies. All attendees are asked to sign a confidentiality waiver prior to each meeting to ensure privacy and to increase the sharing of personal experiences. In addition to these meetings, students have access to a website developed by MtG that includes a list of local mental health resources, a calendar of MtG events,

Keywords: Mental health; Depression; Stigma; Burnout; Support; Group

Page 1 | UOJM ePub | January 2017 
and interesting research articles pertaining to mental health.

As per the recommendations of the CMA, the overall goal of MtG is to create a strong social network that enables students to feel well supported by their peers during their medical training. It also aims to reduce stigma by encouraging participants to share personal stories related to mental health. It is expected that MtG will prevent negative mental health consequences amongst medical students, such as depression and suicidality, by changing the way medical students understand and discuss mental illness at the onset of their training.

MtG differs from other mental health programs currently offered at medical schools as it is a solely peer-based program, meaning that students are involved in all stages of program development, organization, and implementation. Although extensive mental health resources exist at the University of Ottawa, such as counselling and career services, formal peer-based programming is less common. Similar programs have been created at the University of Toronto and Western University, although very few peerbased medical school programs exist on a national level. In 2010, the Mental Health Commission of Canada (MHCC) published a report entitled, "Making the Case for Peer Support," which highlighted research linking peer-based support with improvements in quality of life, as well as reductions in symptom distress and mental illness-related hospitalizations [5]. Despite peer support programs being a relatively new and underutilized approach to wellness, the MHCC has emphasized the critical importance and effectiveness of peer-based programs as part of its national mental health strategy [5]. As such, in 2013, the MHCC released Guidelines for the Practice and Training of Peer Support, which MtG has been striving to incorporate into regular practice [6]. Overall, MtG aims to create a standardized program in line with the values and recommendations of the CMA and MHCC that can be easily implemented at medical schools across Canada.

The development of MtG has not been without challenges, as can be expected from a program that involves the dissemination of sensitive personal information. An important challenge has been the issue of maintaining student confidentiality. As mentioned, students are required to sign a confidentially agreement. Nevertheless, this does not entirely guarantee that personal information will stay within the MtG participant pool. Secondly, an initial objective of MtG was to have an online forum where students could anonymously share personal stories with registered online viewers. The biggest concern with this was how to appropriately respond to posts that include threatening information describing plans of self-harm or suicide. As such, this component of the program has not been incorporated to date as a reasonable solution remains to be found. As the program continues to evolve, we expect to find solutions to deal with these challenges more effectively to ensure that MtG provides medical students with a safe, secure, and confidential forum to discuss mental health.

As research continues to shed light on the significance and consequences of mental illness amongst medical students, we believe MtG and similar programs will provide medical students with a supportive social community to discuss personal experiences and issues pertaining to mental health. We expect this to ultimately reduce negative stigma perceptions surrounding this topic amongst medical trainees and professionals. Furthermore, we hope that as more programs like MtG are implemented across Canada we will see a paradigm shift towards discussion of mental illness in the medical professional community, as well as an increase in the utilization of mental health supports.

For more information about the MtG program at the University of Ottawa, please visit www.letsmindthegap.com or e-mail mindthegapottawa@gmail.com.

\section{REFERENCES}

1. Dyrbye LN, Thomas MR, Shanafelt TD. Medical student distress: causes, consequences, and proposed solutions. Mayo Clin Proc. 2005;80(12): 1613-22.

2. Dyrbye LN, Thomas MR, Massle FS, et al. Burnout and suicidal ideation among U.S. medical students. Ann Internal Med. 2008;149(5):334-41.

3. Schwenk TL, Davis L, Wimsatt LA. Depression, stigma, and suicidal ideation in medical students. JAMA. 2010;304(11):1181-90.

4. Moloughney B. Physician Health Matters: A Mental Health Strategy for Physicians in Canada [Internet]. Ottawa (ON): Canadian Medical Association; 2010 February [cited 2016 August 21]. Available from: https://www.cma.ca/ Assets/assets-library/document/en/practice-management-and-wellness/ Mentalhealthstrat_final-e.pdf.

5. Cyr C, McKee H, O'Hagan M, Priest R. Making the Case for Peer Support: Report to the Peer Support Project Committee of the Mental Health Commission of Canada. Mental Health Commission of Canada [Internet]. Calgary (AB): Mental Health Commission of Canada; 2010 [updated 2016 July; cited 2016 August 21]. Available from: http://www.mentalhealthcommission. $\mathrm{ca} /$ sites/default/files/2016-07/MHCC_Making_the_Case_for_Peer_Support_2016_Eng.pdf.

6. Sunderland K, Mishkin W. Guidelines for the Practice and Training of Peer Support [Internet]. Calgary $(\mathrm{AB})$ : Mental Health Commission of Canada; 2013 [updated 2013 December 2; cited 2016 August 21]. Available from: http://www.mentalhealthcommission.ca/sites/default/files/peer_support_guidelines.pdf. 